\section{SOCIOTERRITORIALIDAD DEL RIESGO DE DESASTRES: UN ESTUDIO DE REPRESENTACIONES SOCIALES EN EL MUNICIPIO DE PIEDECUESTA, COLOMBIA}

Deysi Ofelmina Jerez-Ramírez ${ }^{1 *}$

\section{RESUMEN}

Esta investigación ha tenido como objetivo principal el comprender la socioterritorialidad del riesgo de desastres a partir del análisis de las Representaciones Sociales (RS) elaboradas en contextos compartidos de vulnerabilidad y exposición. Con este propósito, se ha indagado en las narrativas y en las imágenes construidas por la población utilizando herramientas como la cartografía social, los cuestionarios de asociación libre y las entrevistas semiestructuradas a profundidad. El estudio hace parte de una investigación llevada a cabo entre 2014 y 2019, con población de la zona urbana, rural y periférica del municipio de Piedecuesta, Colombia. La metodología se sustenta en una triangulación de métodos cualitativos que son característicos de los trabajos sobre RS y los estudios sociales de los desastres. Los resultados evidencian la influencia de doble vía entre los conocimientos-prácticas elaboradas colectivamente entorno al riesgo de desastres y la agencia social que el sujeto ejerce sobre su propio territorio.

\section{PALABRAS CLAVES}

Riesgo de desastres, Representaciones sociales, Socioterritorio, Narrativas, Imágenes colectivas

\section{SOCIO-TERRITORIALITY OF RISK: A STUDY OF SOCIAL REPRESENTATIONS IN THE MUNICIPALITY OF PIEDECUESTA, COLOMBIA}

\begin{abstract}
This investigation aims to better understand the socio-territoriality of disaster risk from the analysis of Social Representations (SR) elaborated in shared contexts of vulnerability and exposure. For this purpose, the narratives and images constructed by a selected population have been investigated using tools such as social cartography, free association questionnaires, and detailed semistructured interviews. The study is part of an investigation carried out between 2014 and 2019, with a population from the urban, rural and peripheral areas of the municipality of Piedecuesta, Colombia. The methodology is based on a triangulation of qualitative methods that are characteristic of the works on SR and the social studies of disasters. The results show the two-way influence between the knowledge-practices collectively elaborated around disaster risk and the social agency that subjects perform over their own territory.
\end{abstract}

\section{KEYWORDS}

Disaster risk, Social representations, Socio-territory, Narratives, Collective images

\author{
1. Instituto de Investigación \\ en Gestión de Riesgos \\ y Cambio Climático, \\ Universidad de Ciencias y \\ Artes de Chiapas, Chiapas, \\ México. \\ *Autor de correspondencia: \\ deysi.jerez@unicach.mx \\ DOI: \\ https://doi.org/10.55467/ \\ reder.v6i1.88
}

\section{RECIBIDO}

20 de junio de 2021

\section{ACEPTADO}

16 de septiembre de 2021

PUBLICADO

1 de enero de 2022

\section{Formato cita}

Recomendada (APA): Jerez-Ramírez, D.O. (2022).

Socioterritorialidad del Riesgo de Desastres: Un Estudio de Representaciones Sociales en el Municipio de Piedecuesta, Colombia. Revista de Estudios Latinoamericanos sobre Reducción del Riesgo de Desastres REDER, 6(1), 124141. https://doi.org/10.55467/ reder.v6i1.88

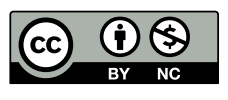

Todos los artículos publicados en REDER siguen una política de Acceso Abierto y se respaldan en una Licencia CreativeCommons Atribución-NoComercial 4.0 Internacional.

Revista de Estudios Latinoamericanos sobre Reducción del Riesgo de Desastres (REDER)

Diseño: Lupe Bezzina 


\section{INTRODUCCIÓN}

La Reducción del Riesgo de Desastres (RRD) representa uno de los principales desafíos para el desarrollo de las comunidades más vulnerables del planeta.

El Decenio Internacional para la Reducción de Desastres Naturales en los años noventa, acentuó el interés de las naciones en la gestión integral del riesgo como una estrategia para el crecimiento económico, el aumento de la calidad de vida de la población y la conservación ambiental. Dicho interés permaneció latente al inicio del nuevo siglo, aunque el concepto de "desastres naturales" fue ampliamente cuestionado (Maskrey, 1993) y reemplazado, finalmente, por la noción de riesgo de desastres (ONU, 2005; Tercera Conferencia Mundial sobre la Reducción de los Desastres, 2015).

En la Declaración del Milenio (ONU, 2000), la reducción de los desastres se impulsó como un reto para el aumento de las capacidades sociales e institucionales ante los peligros del entorno, conservando vigencia en los ahora Objetivos de Desarrollo Sostenible como meta específica en cinco de estos diecisiete objetivos (ONU, 2015). Paralelamente, la actual plataforma internacional para la RRD, el Marco de Acción de Sendai, plantea la necesidad de superar esquemas verticales de decisión y desarrollar estrategias de gobernanza que permitan la coordinación de múltiples actores.

No obstante, en gran parte de los países latinoamericanos, el riesgo de desastres se sigue abordando desde sólo una perspectiva técnica, bajo una óptica de ingeniería del medio ambiente (Chmutina et al., 2021; Preciado, 2007), lo cual reduce el espacio participativo de la población y las comunidades. Este contexto justifica el interés que la academia de ciencias sociales de la región ha mantenido en el estudio de aquellas dimensiones que remiten a la naturaleza social de la problemática, así como a la construcción colectiva de soluciones.

El origen multidimensional de los desastres y la complejidad del riesgo se ha convertido en el eje central de diversos estudios holísticos que dejaron de lado al reduccionismo del paradigma fisicalista (Hewitt, 1983) para construir un enfoque alternativo (Maskrey, 1993; García, 2005; OliverSmith et al., 2017; Sevillano, 2021). La relación vulnerabilidad-amenaza, base de este nuevo enfoque, acentuó la importancia de aquellas investigaciones preocupadas por tratar los efectos simbólicos y materiales que el riesgo ejerce sobre el territorio, más allá de las características físicas y desarticuladas de estas variables.

El riesgo de desastres se plantea entonces como una construcción social, misma que compromete el acervo de sentido común al cual el sujeto cognoscente recurre, de manera cotidiana, para el reconocimiento de su entorno, aquel que también comparte una sociogénesis.

El presente trabajo se inscribe en esta perspectiva holística y multidimensional. Tiene como objetivo principal comprender la socioterritorialidad del riesgo a partir del análisis de las RS elaboradas en contextos compartidos de vulnerabilidad y exposición, indagando en las narrativas e imágenes construidas colectivamente por la población de estudio. Presenta parte de los resultados de una investigación (Jerez-Ramírez, 2018) llevada a cabo con actores comunitarios e institucionales en Piedecuesta, Colombia, lugar con recientes antecedentes como la ola invernal 2010-2011 y la avalancha de 2020. La investigación desarrollada por Jerez-Ramírez (2018) se interesó en identificar un sistema de categorías específicas para el abordaje del riesgo de desastres como un fenómeno representacional que se puede analizar desde las dimensiones sociocognitiva, socioestructural y socioterritorial. El artículo rescata los resultados asociados con esta última categoría, hallazgos que se han seguido actualizando con talleres, entrevistas y cuestionarios.

El artículo es constituido por seis apartados. En el primero, se realiza una reflexión en torno al estudio social de los desastres, al concepto totalizante-integrador de la socioterritorialidad del riesgo y a la Teoría de las Representaciones Sociales (TRS). En la segunda y tercera sección se presentan la contextualización de la zona de estudio y la explicación de la metodología aplicada, respectivamente. Los resultados son expuestos en la cuarta parte y se analizan en el apartado de discusión (quinta sección). Finalmente, se detallan algunas conclusiones de la investigación (sexta sección).

\section{SOPORTE TEÓRICO-CONCEPTUAL}

A continuación, se presentan los enfoques y conceptos que configuran el marco teórico-conceptual de la investigación. 


\section{Enfoque social de los desastres}

El enfoque social básicamente propone una interpretación global de los desastres con el objetivo de abordar la complejidad que reviste la problemática. La necesidad de incorporar a los diagnósticos de riesgo, variables antes excluidas como los modelos de desarrollo, las condiciones socioeconómicas de la población, la percepción social y la apropiación simbólica del territorio, llevaron a cuestionar el paradigma fisicalista o dominante (Hewitt, 1983) de los desastres, centrado en perfeccionar los métodos y herramientas para el monitoreo de los fenómenos físicos potencialmente peligrosos.

En la década de los setenta y ochenta, los patrones de concentración y distribución de las pérdidas, en términos relativos, frente a la ocurrencia de desastres en las regiones en vías de desarrollo y las poblaciones más susceptibles de algunos países desarrollados, generaron interés académico, especialmente desde las ciencias sociales. Los estudios de vulnerabilidad y exposición social como escenarios compartidos por gran número de personas en el planeta, tomaron relevancia como temas complementarios a los trabajos sobre amenazas y peligros para, posteriormente, convertirse en un campo específico de investigación (Anderson y Woodrow, 1989; Wilches-Chaux, 1993; Lavell, 1996).

Lo que podemos denominar como un proceso de "desnaturalización" de los desastres, supuso el reconocimiento de la vulnerabilidad y la amenaza como variables fundadoras del riesgo y, por tanto, como conceptos elementales para el estudio social, variables que poseen una innegable manifestación -material y simbólica- en el territorio habitado. La amenaza que es conceptualizada por los organismos internacionales como una "condición peligrosa" de origen diverso (ONU, 2009: 5), también puede entenderse como "la expresión extrema de lo que, en otro ámbito, se conoce como recursos" (Martínez, 2009: 251).

La vulnerabilidad, por su parte, es una dimensión que se descubre muy ligada a las trayectorias y dinámicas del esquema económico imperante y a elementos profundos del sistema político, social y cultural de los países (O'Keefe et al., 1976; Mansilla, 1996; Pereira y Raju. 2020; SandovalDíaz, 2020). Condiciones previas de susceptibilidad que caracterizan un entramado social y que pueden potencializarse en contextos pos-desastre desde sus diferentes manifestaciones: (i) socioeconómico; (ii) físico-estructural y (iii) cultural-político (Anderson y Woodrow, 1989).

El carácter multidimensional del riesgo ha permitido el abordaje teórico-metodológico de elementos tanto objetivos como subjetivos del binomio vulnerabilidad-amenaza. El enfoque sociológico (Beck, 2002; Luhmann, 2006) reconoce al riesgo como un constructo social que deriva de la interacción de experiencias sociales, percepciones colectivas e interpretaciones compartidas de una realidad en incertidumbre.

\section{Socioterritorialidad del riesgo y la Teoría de representaciones sociales}

El territorio representa "experiencia" -territorialidad- y como una experiencia, dificilmente puede abordarse a partir de las generalidades. La territorialidad hace relación a una vivencia diversificada que integra aspectos cognitivos, culturales, históricos, además de relaciones de poder; también se asocia a la "práctica espacial" de grupos humanos sobre el lugar habitado, por lo que conviene hablar de una socioterritorialidad, ya que la "territorialidad es una característica central de los agenciamientos" (Herner, 2009: 166).

Se habla de un ejercicio de organización y desorganización de lo material y simbólico, acción identitaria ${ }^{1}$ de control sobre el entorno socialmente [de]construido. El término des-reterritorialización (Herner, 2009; Haesbaert; 2013; Argudo, 2019) hace alusión a los procesos que permiten la producción de espacios (territorialización) como territorios, incluyendo la adopción de determinados atributos: poder y control. Existe una alternancia entre periodos de desgaste no totales (Haesbaert, 2013) de estos atributos (desterritorialización) y la reapropiación de los mismos (reterritorialización) para la generación de nuevos y múltiples espacios.

"Todo proceso y toda relación social implican siempre y simultáneamente una destrucción y una reconstrucción territorial" (Haesbaert, 2013: 13). La definición del escenario natural y social en donde se generan e interactúan los componentes de amenaza y vulnerabilidad, requiere del estudio de estos procesos para entender la forma en que los sujetos cognoscentes configuran, organizan y transforman el entorno. El estudio social del riesgo posibilita un diagnóstico integral: a)
1. Los tiempos identitarios del pasado y presente se entretejen con la noción de futuro, tiempo cercano al riesgo; la incertidumbre de lo desconocido que adopta diferentes matices desde la noción de territorialidad. 
la evaluación cuantitativa de los atributos estadísticos de vulnerabilidad y exposición territorialmente manifiesta, b) el impacto físico del fenómeno sobre los grupos sociales, y c) la interpretación cualitativa de aquellos elementos simbólico-significantes que configuran el objeto de estudio en un contexto determinado. Para este último objetivo, en el que se centra este estudio, se recomienda el enfoque de representaciones sociales.

La Teoría de Representaciones Sociales (TRS) se ha encargado del estudio de aquellas "imágenes que condensan un conjunto de significados; sistemas de referencias que nos permiten interpretar lo que nos sucede, e incluso, dar un sentido a lo inesperado" (Jodelet, 1986: 472). La TRS concibe al sujeto y su ambiente como una unidad indivisible y a la realidad como un constructo que se puede explicar a partir de la interpretación social, por lo que desde hace ya tiempo se han realizado importantes acercamientos al estudio de problemas socioambientales -en el que se inscribe el tema de RRD- desde el concepto moscoviciano (Reigota,1990; Calixto, 2008; Toscana y Valdez, 2014; Espinosa, 2020).

(...) Una representación social se construye en y con la cultura y por lo tanto no es un esquema psicológico ni cognitivo individual. Las representaciones sociales son productos sociales derivados de la interacción y por ende su naturaleza es relacional. No puede existir una representación social aislada, sino que siempre se desarrolla, circula y transforma en relación con otras representaciones. Además, las representaciones sociales no constituyen la realidad -no tienen tal pretensión- sino que son una aproximación a esta (Serrano, 2016: 4-5).

Ya Moscovici $(1979 ; 1996)$ advertía de la capacidad transformadora de los sujetos y grupos, más allá de un rol adaptativo. La construcción social del riesgo como objeto de estudio requiere del análisis de los factores emocionales, interactivos, de objetivación, anclaje y externalización que permiten el intercambio entre el sujeto social y su entorno. Bajo este tenor, el control y el poder ejercido territorialmente descansan en la capacidad creativa de transformar mediante la interacción comunicativa y el pensamiento práctico, aspectos también presentes en la formación de conocimientos y en la toma de decisiones en torno al riesgo de desastres.

\section{CONTEXTO: DIAGNÓSTICO VULNERABILIDAD-AMENAZA}

El área de estudio corresponde al municipio de Piedecuesta, localidad colombiana con una población de 182,959 habitantes, según proyecciones de 2018 -2035 (DANE, 2018), ubicada muy cerca de la capital del departamento -a unos $17 \mathrm{~km}$ de Bucaramanga. El casco urbano alberga más del $80 \%$ de la población, pese a que esta zona solamente representa el $3.3 \%$ del territorio total municipal.

Piedecuesta ha experimentado desde mitad del siglo pasado, tal como lo muestra la Figura 1 , el aumento de población del casco urbano municipal por las constantes migraciones desde la zona rural y otras localidades, generando una elevada presión sobre esta zona, el aumento de la vulnerabilidad social, mayor incidencia delictiva y graves problemas de contaminación ambiental. Respecto a este último aspecto, se considera que la contaminación de importantes cuerpos de agua como el río de Oro, la quebrada Verdum, la quebrada Palmira, la quebrada Suratoque, el río Hato y la quebrada Guatiguará, se debe al mal manejo de residuos provenientes de las urbanizaciones cercanas al área de influencia, así como al vertimiento directo de sustancias derivadas de la actividad avícola y la curtiembre (Alcaldía de Piedecuesta, 2020).

Simultáneo al éxodo del campo a la ciudad, el acelerado ritmo de urbanización en Piedecuesta responde a dos importantes fenómenos de emplazamiento poblacional: a) el incremento de proyectos de urbanización como respuesta a la saturación física de otros municipios cercanos a la capital departamental (Bucaramanga), teniendo en cuenta que, en comparación con otras áreas de la zona metropolitana, la localidad piedecuestana presenta la mayor extensión de territorio rural y suelos de expansión; b) la migración intradepartamental -Magdalena Medio Santandereano, Soto Norte y Rionegro- e interdepartamental -Norte de Santander, Arauca, Bolívar y sur del Cesar- de población desplazada, considerando que Piedecuesta, desde años atrás, ha fungido como municipio receptor de grupos vulnerados por el conflicto armado interno y el desarrollo de desastres (Alcaldía de Piedecuesta, 2020). 
Frecuentemente la población migrante y desplazada se ha establecido en barrios precarios y asentamientos irregulares en zonas de alta amenaza (pendientes, laderas, caída de rocas y áreas inundables), ya que son los únicos terrenos accesibles a los inmigrantes pobres. "Los asentamientos humanos ilegales del municipio se dividen en 4 sectores: S1. Granadillo, S2. Barroblanco, S3. Guatiguará, S4. Aislados. Se estima que la población en estos asentamientos supera las 20 mil personas" (Alcaldía de Piedecuesta, 2020: 112). La clase media, por el contrario, se ubica en zonas menos peligrosas.

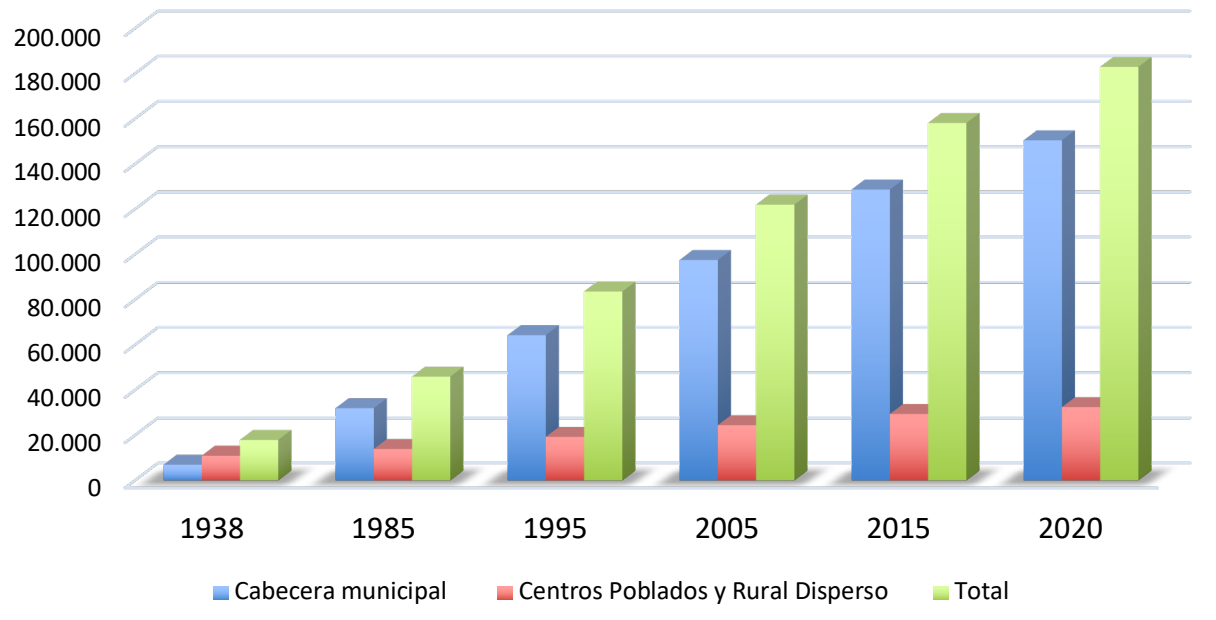

Figura 1. Población rural y urbana del municipio de Piedecuesta 1938-2020

Fuente: Autora, 2022, con información de base DANE, censo general de población (1938); proyección de población (1985-2017/2018-2070).

La morfología del territorio garrotero se caracteriza por diversidad de montañas, valles, colinas y mesetas que determinan el variado clima de la región. Piedecuesta "hace parte de tres cuencas hidrográficas: la cuenca del río Lebrija Alto - Subcuenca Lebrija Alto (jurisdicción de la $\mathrm{CDMB}$ ), cuenca del río Sogamoso (Jurisdicción de la CAS) y cuenca Medio y Bajo Chicamocha - Subcuencas de Umpalá y Manco" (Alcaldía de Piedecuesta, 2020: 136). De igual forma, hacen parte del municipio 15 quebradas que funcionan como fuentes de agua potable y sistemas de regadío para cultivos; también son utilizadas para extracción de arena y transporte de aguas residuales, actividades con un fuerte impacto ambiental.

La abundante hidrografía del municipio lo sitúa en la zonificación de recursos nacionales como un territorio productor de agua, esto por su ubicación en la Cordillera Oriental (Jerez-Ramírez, 2018). No obstante, en los últimos años, los principales riesgos de desastres corresponden a incendios forestales $(87,5 \%)$ relacionados con extensas temporadas de sequía y actividades antrópicas que han afectado las zonas rurales y forestales de la localidad. El porcentaje de ocurrencia de este tipo de desastres está muy por encima de otros fenómenos como las inundaciones $(12,5 \%)$, eventos que han afectado principalmente a la población de asentamientos irregulares (Alcaldía de Piedecuesta, 2020).

De acuerdo al Plan Municipal para la Gestión del Riesgo de Desastres, incluido en el Plan de Desarrollo Municipal (Alcaldía de Piedecuesta, 2020), el Índice Municipal de Riesgo de Desastres ante fenómenos hidrometeorológicos es de 45, 3 puntos -en una escala de 0 a 100-, por lo que se considera que el nivel de riesgo al que está expuesta la población es media alta. Como corolario, la inversión para la gestión del riesgo se ha dividido en cuatro rubros principales: reducción del riesgo $(49 \%)$, conocimiento del riesgo $(28 \%)$, manejo de la emergencia $(22 \%)$ y el fortalecimiento institucional (1\%). Es importante destacar que en los instrumentos municipales para la RRD se siguen priorizando las acciones ingenieriles orientadas a la mitigación, ubicando en segundo plano a las estrategias de prevención efectivas que incorporan aspectos sobre la vulnerabilidad social, la percepción compartida del riesgo y las prácticas comunitarias necesarias para la gestión.

A modo de resumen, de acuerdo a datos recopilados durante la investigación, el municipio de Piedecuesta presenta condiciones de vulnerabilidad en varios sentidos: bajos niveles de ruralidad por abandono del campo, concentración de bienes y servicios en el área urbana, deficiencias en cobertura de servicios básicos (educación, salud, deporte, cultura, vivienda, servicios públicos y 
seguridad), asentamientos precarios en zonas de alto riesgo, presencia de población desplazada e inexistencia de políticas eficaces de atención -siendo las localidades periféricas las áreas de mayor recepción-, amenazas asociadas a actividad geológica y a eventos hidrometeorológicos, alta vulnerabilidad del sector base de la economía municipal ante los cambios extremos del clima y malas prácticas agro-industriales en el uso del suelo y del recurso hídrico.

\section{Breve caracterización de las zonas de estudio}

La comunidad periférica de Nueva Colombia (ver Figura 2 y 3 ), ubicada en un espacio rural2, pero con evidentes procesos de periurbanización, es un asentamiento humano precario constituido por un aproximado de 500 familias, hogares que son cubiertos por el servicio de agua potable, aunque no cuentan con sistema de alcantarillado. Las aguas residuales son depositadas en pozos sépticos y desaguadas por terrenos escarpados, generando serios problemas de contaminación. Presenta una alta vulnerabilidad física tanto por la ubicación del asentamiento, como por la calidad y resistencia de los materiales utilizados en las viviendas, la mayoría de autoconstrucción. Dada la topografía del terreno, la acumulación de agua en las zonas de laderas genera una exposición continua a deslizamientos de tierra y caída de rocas, condición que se agrava durante la temporada de lluvia. El asentamiento fue conformado a partir de los emplazamientos irregulares de población desplazada por el conflicto armado interno, migrantes que llegaron al municipio durante la década de los noventa. Además del uso y disposición del agua o desagües, otro asunto vinculado al tema del riesgo es la negativa de la municipalidad a la entrega de escrituras de terrenos, atendiendo a las recomendaciones y observaciones de los estudios de amenaza desarrollados en el lugar. Aquí se resalta como las $\mathrm{RS}$ del riesgo se asocian a diversidad de problemáticas que no siempre tienen asociación directa con fenómenos naturales, pero que, sin duda, se vinculan con la incertidumbre que, en todo caso, se manifiesta territorialmente.

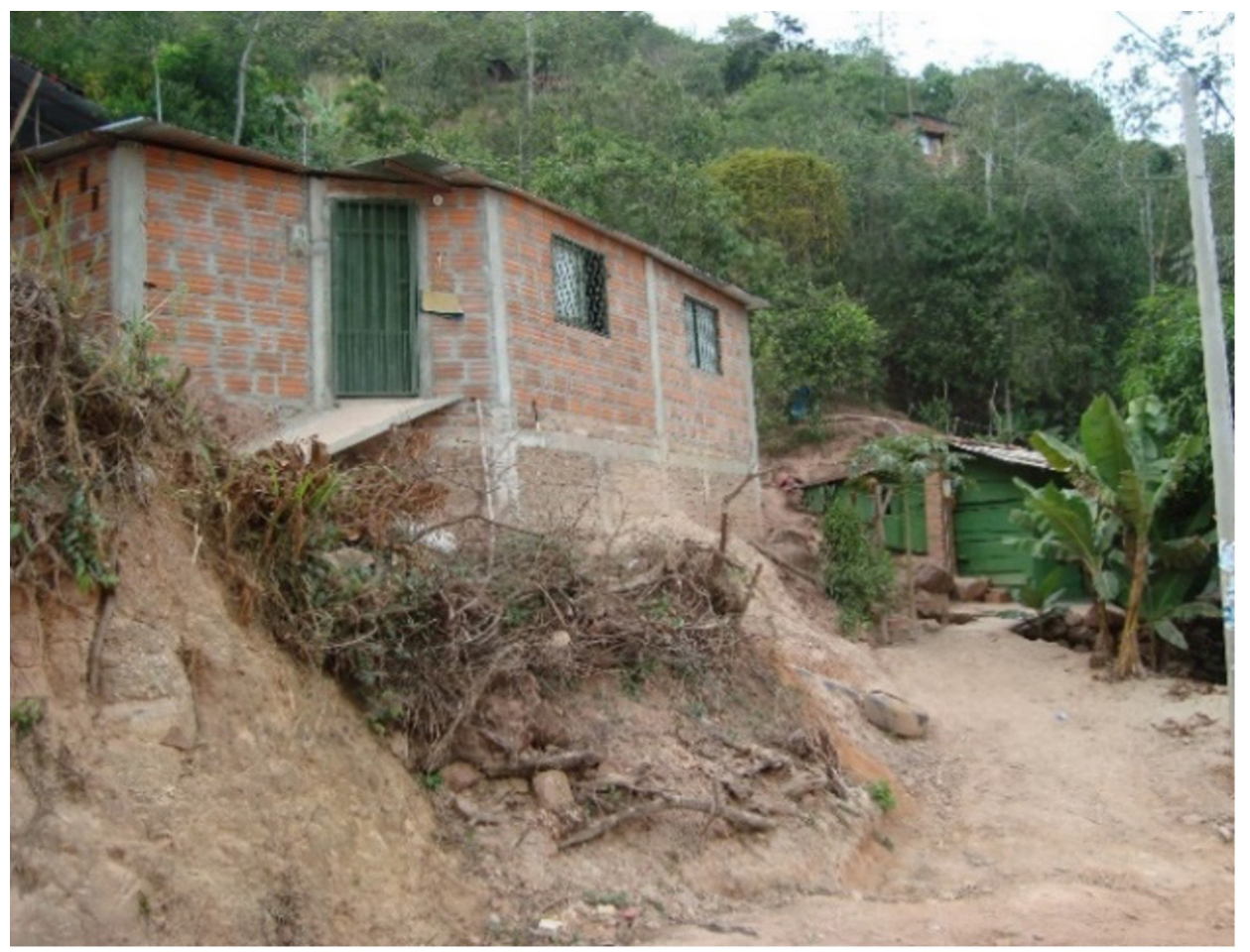

Figura 2. Vivienda en la periferia municipal Fuente: Autora, 2019.

La zona rural del estudio corresponde a la localidad El Duende (ver Figura 4), fracción veredal que hace parte del municipio piedecuestano. La población de la zona manifiesta una alta exposición a temporadas de sequía e incendios forestales (ver Figura 5). Se ha generado un incremento en la vulnerabilidad de la economía y la salud de sus habitantes ante la percibida variabilidad climática. En la vereda, con un aproximado de 80 familias, los eventos por sequía se han prolongado en los últimos años; dicho escenario de amenaza se relaciona con tres situaciones que han afectado a la población campesina, especialmente de esta zona: 1) las alteraciones en los ciclos de lluvias; 2) el déficit en cobertura del servicio de agua potable; y 3) el acaparamiento del recurso hídrico
2. En la vereda de Guatiguará se ubican tres asentamientos irregulares de gran crecimiento en las últimas décadas, a saber: Altos de Guatiguará, La Vega y Nueva Colombia. 
-canalización, obstrucción, represamiento y bombeo de agua- por parte de las granjas avícolas -actividad más importante de la región- y fincas ganaderas.

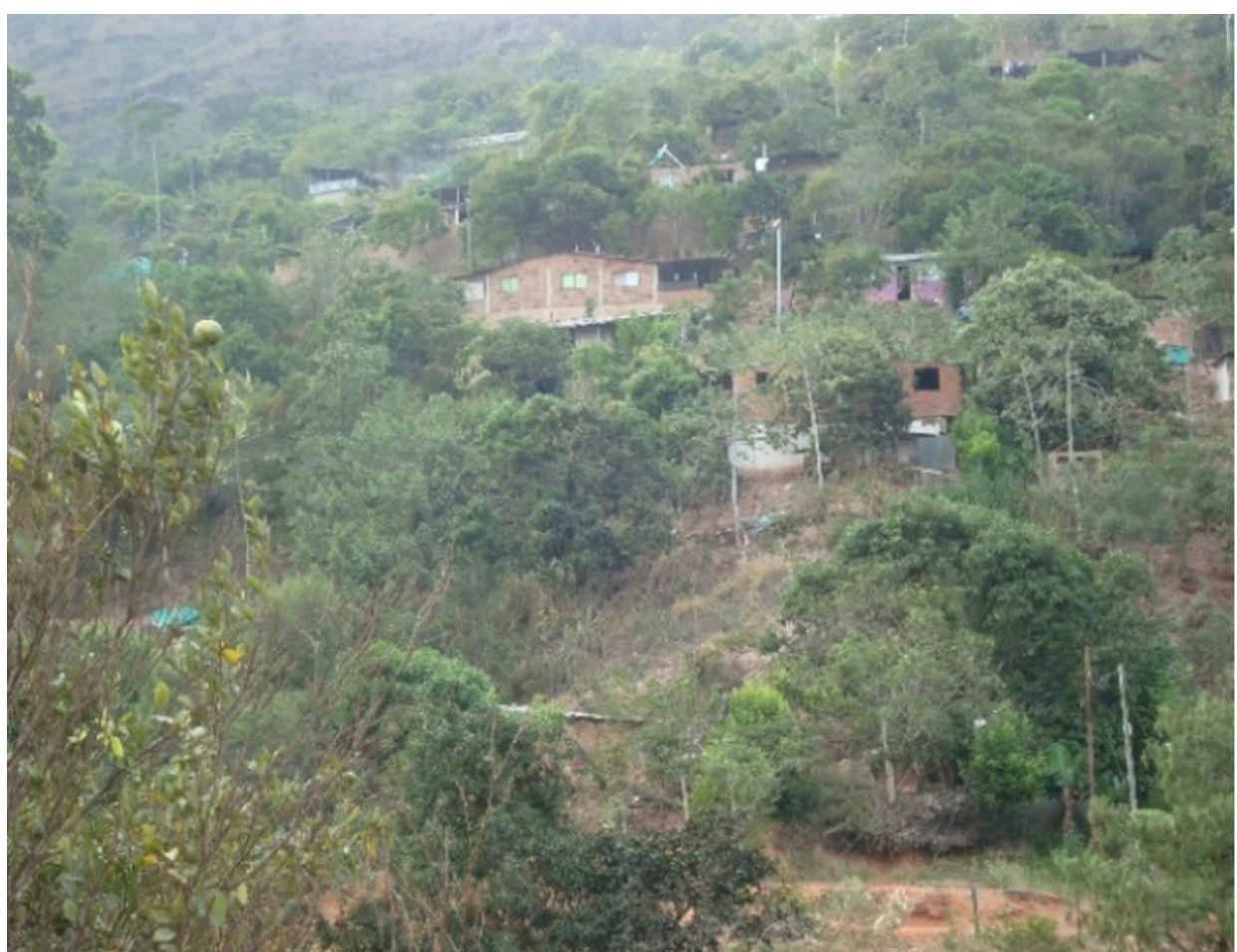

Figura 3. Sector de Nueva Colombia Fuente: Autora, 2020.

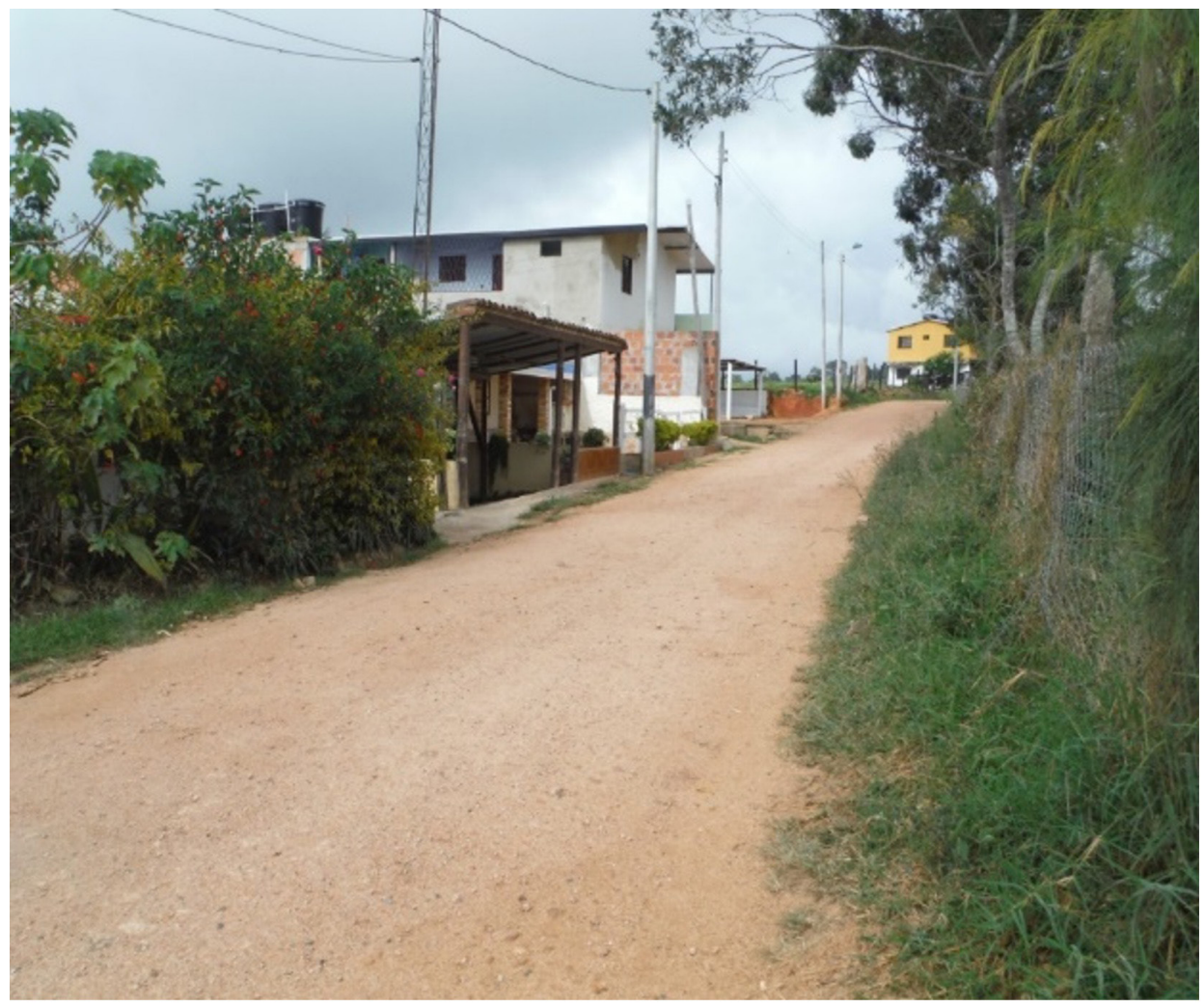

Figura 4. Vereda El Duende

Fuente: Autora, 2020 


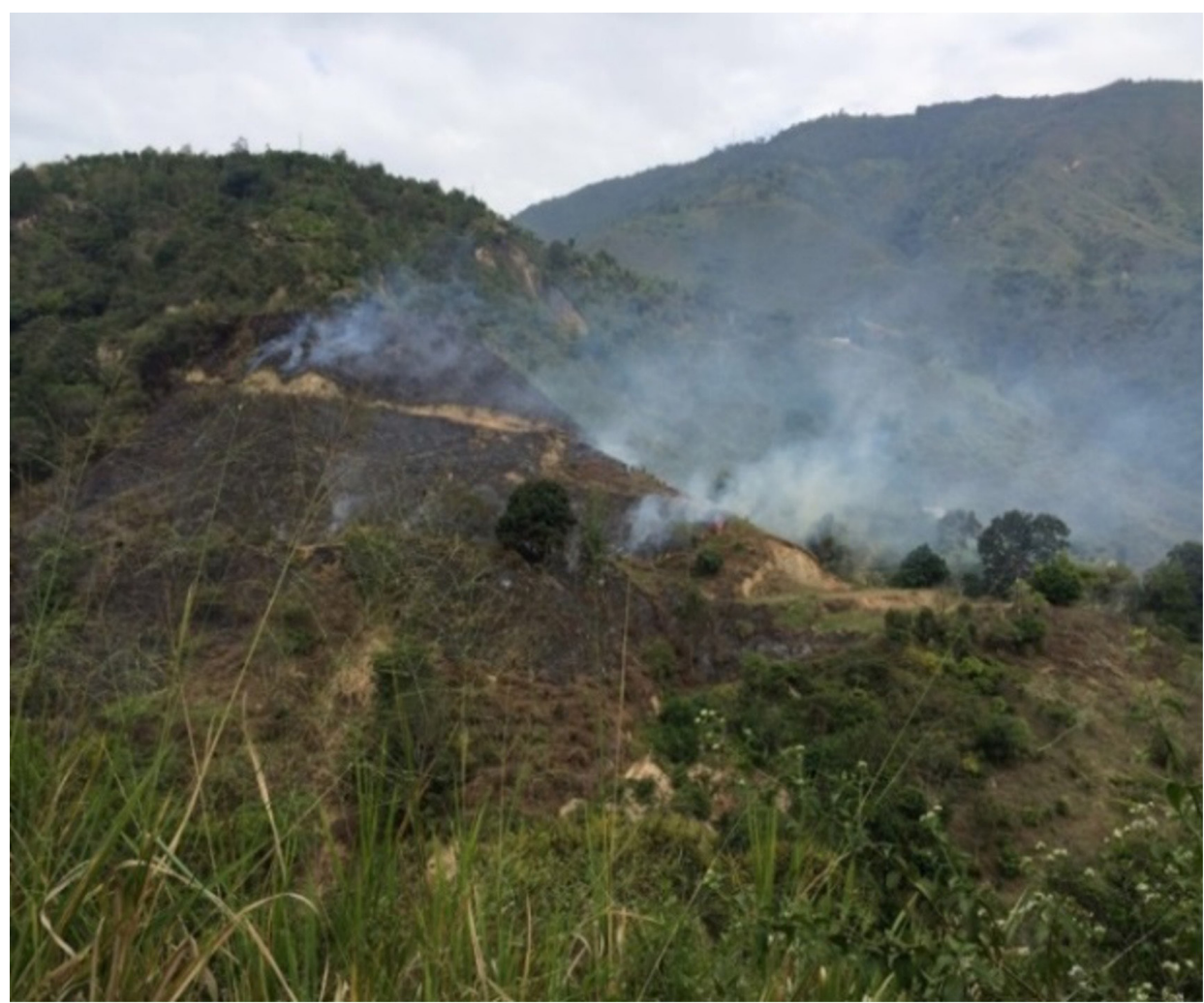

Figura 5. Incendios forestales en la zona rural Fuente: Autora, 2020 .

Finalmente, el barrio Barro Blanco (área urbana) es un sector construido como proyecto público nacional de vivienda de interés social, con más de treinta años de antigüedad, que está situado al suroccidente del municipio (ver Figura 6). Como principales amenazas se señalan la exposición a inundaciones, mitigada hace algunos años por la construcción de un nuevo muro de contención (2015), y la contaminación del río (Río de Oro) que colinda con el sector. Otras problemáticas identificadas en los talleres de cartografía social son las condiciones de inseguridad que se han incrementado en el barrio por la presencia de vendedores de estupefacientes y delincuentes que se han tomado los espacios públicos. De acuerdo con los testimonios, la población de mayor riesgo son los adolescentes, niñas y niños (infantes y adolescentes), expuestos al consumo de drogas y a la violencia por robo. Frecuentemente, los habitantes del lugar asocian a la venta y distribución de drogas a los grupos que provienen de la periferia municipal, como es el caso del sector de Nueva Colombia.

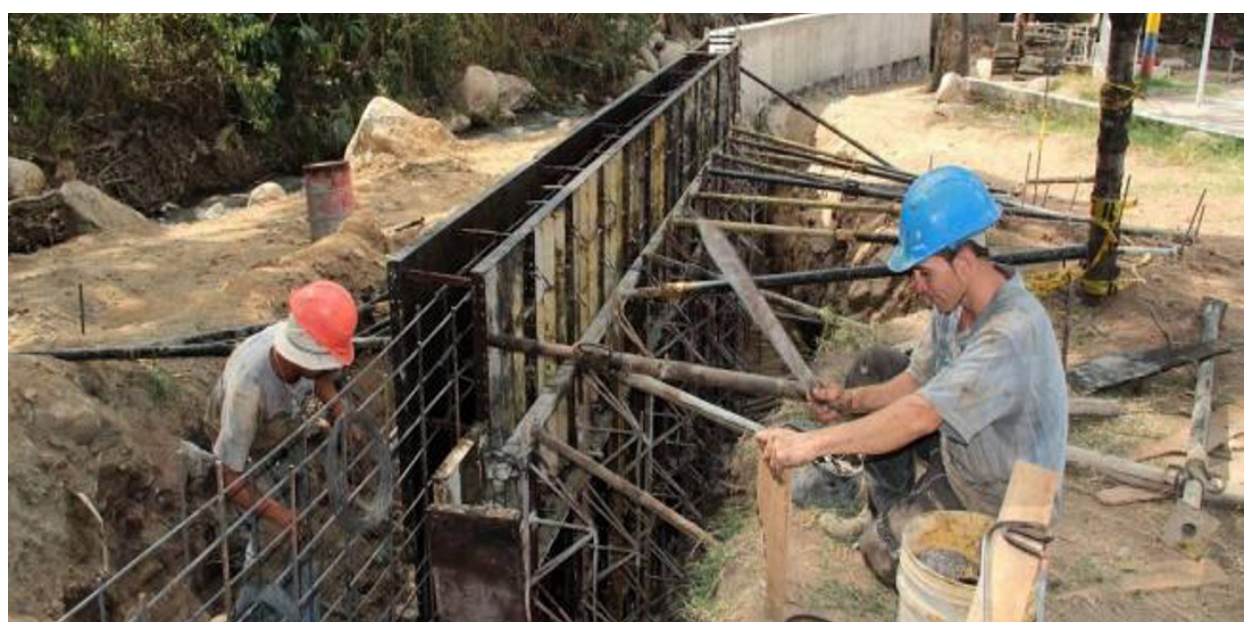

Figura 6. Construcción del muro en el barrio Barro Blanco

Fuente: Vanguardia, 2020. Disponible en: http://www.vanguardia.com 


\section{METODOLOGÍA}

La exposición de la población piedecuestana ante diversos fenómenos naturales y actividades antrópicas, ha impulsado a las autoridades locales a adherirse a la discusión internacional en torno a la comprensión y gestión del riesgo de desastres. Sin embargo, el concepto institucionalizado mediante normas, programas y proyectos de gobierno, no necesariamente recupera las experiencias, nociones e interpretaciones de la comunidad ante esta problemática.

Bajo este tenor, el trabajo pretende comprender las RS a partir de la narrativa y la imagen socialmente construida de los contextos de susceptibilidad ante desastres, desde un enfoque territorial, a través de la triangulación de técnicas de investigación social aplicadas a actores comunitarios e institucionales del municipio. Los instrumentos de recolección de datos se trabajaron a partir del esquema de momentos metodológicos ${ }^{3}$, con el fin de organizar la información que provenía de los métodos interrogativos y asociativos (primer momento), enfocados en analizar los contenidos y procesos de las RS, así como de los instrumentos propios del estudio social de los desastres más utilizados para identificar los elementos del riesgo (amenaza, exposición, vulnerabilidad), como es el caso de la cartografía social (segundo momento).

Se realizaron 12 entrevistas (presenciales) semi-estructuradas a profundidad: 3 a actores institucionales, 3 a residentes de zonas rurales (vereda el Duende), 3 a habitantes de la periferia (sector Nueva Colombia) y 3 del área urbana (barrio Barro Blanco). La guía para entrevistas ${ }^{4}$ quedó constituida por preguntas abiertas, manejadas como preguntas base (11 en total). La idea de este esquema es que el sujeto informante tenga libertad de expresar todo aquello que desee comunicar a partir de un estímulo inicial (pregunta base). Las preguntas base se clasificaron en cinco temas principales que, a su vez, representaron diferentes secciones de la entrevista: I) datos personales; II) estructura familiar; III) vivienda y entorno habitacional; IV) identidad y territorio; y V) percepciones, prácticas y experiencias. Estas categorías surgen de la combinación de preguntas diseñadas para indagar en las siguientes nociones teórico-conceptuales: riesgo y desastre, niveles intra-inter personal e intra-inter grupal, estructura sociocognitiva, base social amplia, relación conocimiento-práctica, territorialidad y tiempos identitarios. La selección de participantes se realizó, inicialmente, por un proceso de bola de nieve que fue derivando en un muestreo por conveniencia, teniendo en cuenta que se requería representación de cada grupo de estudio (rural, urbano, periurbano y actores institucionales).

Durante el trabajo de campo se aplicó la técnica de asociaciones de palabras (Abric, 2001) a un grupo de 25 personas para detectar las evocaciones espontáneas frente al término "riesgo de desastres". Para la aplicación de los cuestionarios se siguieron criterios de selección similares a los implementados en las entrevistas.

También se realizaron 3 talleres con residentes municipales en donde se aplicó la técnica de cartografía social. Para la realización de esta técnica grupal se construyó previamente una guía de cartografía social, la cual se aprovechó de forma simultánea como un instrumento para el diagnóstico de vulnerabilidad-amenaza. El proceso completo se integró, además de los talleres, por recorridos de reconocimiento de las zonas de interés, reuniones previas para la organización de las actividades con líderes comunitarios y encuentros posteriores a los talleres para la socialización de las problemáticas identificadas con el encargado municipal del área de gestión de riesgos. El objetivo principal de la cartografía social fue caracterizar, de manera participativa y colectiva, la representación social del espacio que se construye de acuerdo con las percepciones, sentimientos y conocimientos de los sujetos participantes en torno a la temática de riesgo de desastres. Así, el protocolo de los talleres se constituyó de las siguientes actividades: a) presentación; b) introducción a la cartografía social (indicaciones para el desarrollo del taller y entrega de materiales); c) evocación del territorio habitado; d) elaboración por grupos de la cartografía y ubicación espacial de los componentes del riesgo de desastres (amenazas y vulnerabilidades); e) exposición de la cartografía por parte de los sujetos participantes; y f) reflexión final.

Cabe destacar que la cartografía elaborada individual y colectivamente, es un instrumento ampliamente utilizado en investigaciones sobre RS, memorias colectivas y experiencias de vida en ambientes naturales y construidos (Milgram y Jodelet, 1976; De Alba, 2004, 2006; Martínez, 2015), teniendo en cuenta que la producción gráfica permite profundizar en elementos no verbalizados en la que se incluyen las nociones espaciales recolectadas desde la cartografía social- que hacen parte del fenómeno representacional (Abric, 2001).
3. Se habla de momentos metodológicos con el fin de establecer el conjunto de instrumentos que se han seleccionado dependiendo de cada enfoque teórico, a saber: la TRS y el estudio social de los desastres; no obstante, son fases que se han desarrollado de forma simultáne durante el trabajo de campo.

4. En la guía de entrevistas realizadas a actores institucionales asociados al tema de la gestión de riesgos en el municipio, se adicionó un apartado sobre funciones $y$ labores desempeñadas en el lugar de trabajo. Estas entrevistas permitieron complementar la información para el diagnóstico de vulnerabilidad y amenaza, además de conocer las RS del riesgo de estos actores. Los hallazgos que dan cuenta de diferencias entre actores sociales e institucionales, no se profundizarán en este trabajo. 
Los resultados aquí presentados, analizados desde los discursos y las imágenes elaboradas por los tres grupos de estudio principales (rural, urbana y zona periférica), están contenidos en la dimensión socioterritorial, aunque incorpora elementos propios de las dos dimensiones restantes: sociocognitiva y socioestructural (ver Jerez-Ramírez, 2018).

\section{RESULTADOS}

Los datos recopilados desde la cartografía social y las entrevistas con los actores municipales dan cuenta de la socioterritorialidad piedecuestana como lecturas espaciales y temporales que se complementan, diversifican y eventualmente, se contraponen. Se buscan identificar estas experiencias territoriales simultáneas, pero diferentes, rastreables a partir de la oralidad y la imagen construida por tres grupos poblacionales (urbano, rural y periférico) en torno al fenómeno representacional de interés.

\section{Primer momento. La narrativa del riesgo de desastres y sus implicaciones socioterritoriales}

El testimonio de la población de Nueva Colombia (periferia municipal) ha permitido reconstruir su transición territorial, dando cuenta tanto de daños materiales y físicos, como del alcance psicosocial y cultural de los procesos de salida, traslado y adaptación de la población desplazada. La migración forzada también es reconocida por este grupo como un desastre y un potencial riesgo ante sus condiciones de vulnerabilidad social. La ruptura de lazos familiares y comunitarios, la tristeza, el miedo, la angustia y la desesperación como consecuencias del desarraigo, se suman a los costos económicos por la pérdida de parcelas, casas, enseres y animales que son, además de patrimonio tangible, elementos portadores de significado.

"Sí, nosotros allá dejamos una casa muy bien hecha, junto con los hijos, mi esposo y yo la habíamos hecho, una casita muy bonita, una granja, teníamos animales, teníamos plantas, cultivábamos en fincas vecinas porque nos dejaban tierra para cultivar, entonces, nosotros así, entre todos los hijos en vacaciones, todos trabajábamos, mi esposo en construcción y lo que yo pudiera ayudarle en la labranza. Bueno, llegamos acá, mi esposo se había venido un tiempecito antes que mi persona puesto que él había sido amenazado, entonces, él viendo que ya habían desaparecido muchos, tanto familiares como vecinos y eso, entonces él una noche se vino, anocheció y no amaneció, y vino a parar aquí a Piedecuesta" (Eudora, AC$\mathrm{Pe}$; 65, sector Nueva Colombia).

Dentro de los riesgos asociados a dinámicas naturales, la comunidad señala una alta exposición a fenómenos como deslizamientos de tierra por saturación de agua, caída de rocas y aludes. Empero, los grupos periurbanos cotidianamente movilizan recursos y esfuerzos colectivos para administrar o idealmente reducir las condiciones de vulnerabilidad, y mitigar lo que se consideran como un riesgo permanente: la tenencia irregular de terrenos ${ }^{5}$. La representación actual del riesgo se construye desde la añoranza de las condiciones anteriores a la desterritorialización, proyectada hacia el futuro. Aún para aquellas personas que se vieron obligadas a migrar por otras razones diferentes al conflicto armado interno, el territorio de origen se vincula, generalmente, a sentimientos positivos como la familia, los amigos, las tradiciones y la pertenencia ${ }^{6}$.

Desde la narrativa rural, las irregularidades en la tenencia de predios también se identifican como un riego de desastre, en la medida en que la incertidumbre respecto al aprovechamiento del territorio agrava la vulnerabilidad socioeconómica ante las presiones del ambiente natural (sequías, incendios forestales, variabilidad climática). Los problemas en el registro de parcelas y los conflictos por linderos entre vecinos, son producto de antiguas prácticas de sucesión de padres a hijos que, por lo general, prescindían de acciones jurídicas que validaran la entrega y división de la propiedad. La titularidad conflictiva ha impedido la organización efectiva de la comunidad para la resolución de problemáticas comunes. De acuerdo al mapa de actores realizados en la zona, predominan las relaciones de tensión entre vecinos del sector y con propietarios y trabajadores de las grandes fincas avícolas, especialmente, acusados de acaparamiento del agua.

"Sí, nosotros nos bañábamos ahí, era una quebrada preciosa, no era muy grande, pero tenía unos charquitos donde nos bañábamos y de ahí se sacaba el agua para la casa, para el ganado, para cultivos, mi papá cultivaba, estoy hablando de hace 40 años, y ya metieron las avícolas y se acabó todo" (Gloria, AC-RU; 58, vereda el Duende).

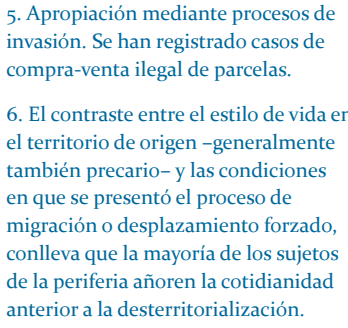


Respecto a lo que denominamos aquí como la oralidad urbana, si bien este grupo no presenta conflictos de tenencia, contrario a los anteriores casos de estudio, sí experimenta una sensación de despojo y de desorientación respecto al disfrute del espacio público, invadido por la prolongación de contextos de vulnerabilidad y problemáticas asociadas a la gente de los asentamientos irregulares. El espacio habitando sigue manteniendo una estrecha relación con aquellos contextos que se circunscriben al ámbito familiar y comunal, razón por la cual, los problemas que afectan el área residencial tienen una mayor relevancia en la valoración y percepción del riesgo. En efecto, las implicaciones sociales de la delincuencia, el consumo de drogas, la inseguridad vial y la contaminación del entorno (factores de riesgo de acuerdo a la población urbana), son expresiones permanentes de desterritorialización que involucran la pérdida paulatina del control territorial.

"Nos organizamos ya hace algún tiempo, pedimos una alarma vecinal, porque en las noches se ha vuelto peligroso andar por ahí, por el barrio. Muchos delincuentes vienen de otras zonas, de afuera, con el riesgo de que varios de los de aquí caigan en malos pasos. Es importante estar atentos" (Leonardo, A.C-Ur; 43, barrio Barro Blanco).

Ante este panorama, las exigencias hacia las autoridades competentes han aumentado por parte de la población urbana: mayor presencia de la policía en la zona, mayor inversión en materia de seguridad y recreación, así como planes de contingencia ambiental más efectivos. De acuerdo a los sujetos entrevistados, el aumento de estas problemáticas se relaciona con el insuficiente esfuerzo institucional para la aplicación de medidas efectivas y la falta de conciencia ambiental de la población.

Los procesos territoriales que se rescatan desde la representación oral del espacio habitado por los grupos de estudio, también dan cuenta de la relación espacial de las dimensiones de vulnerabilidad y amenaza, dimensiones que abarcan diversas problemáticas sociales percibidas y elementos del medio ambiente natural y construido (ver Figura 7). El análisis de esta relación se ha profundizado mediante los productos de las cartografías sociales, ejercicios que, a su vez, evidencian nuevos rasgos (contenido, ubicación, significado) de los diferentes elementos que integran la construcción social del riesgo.

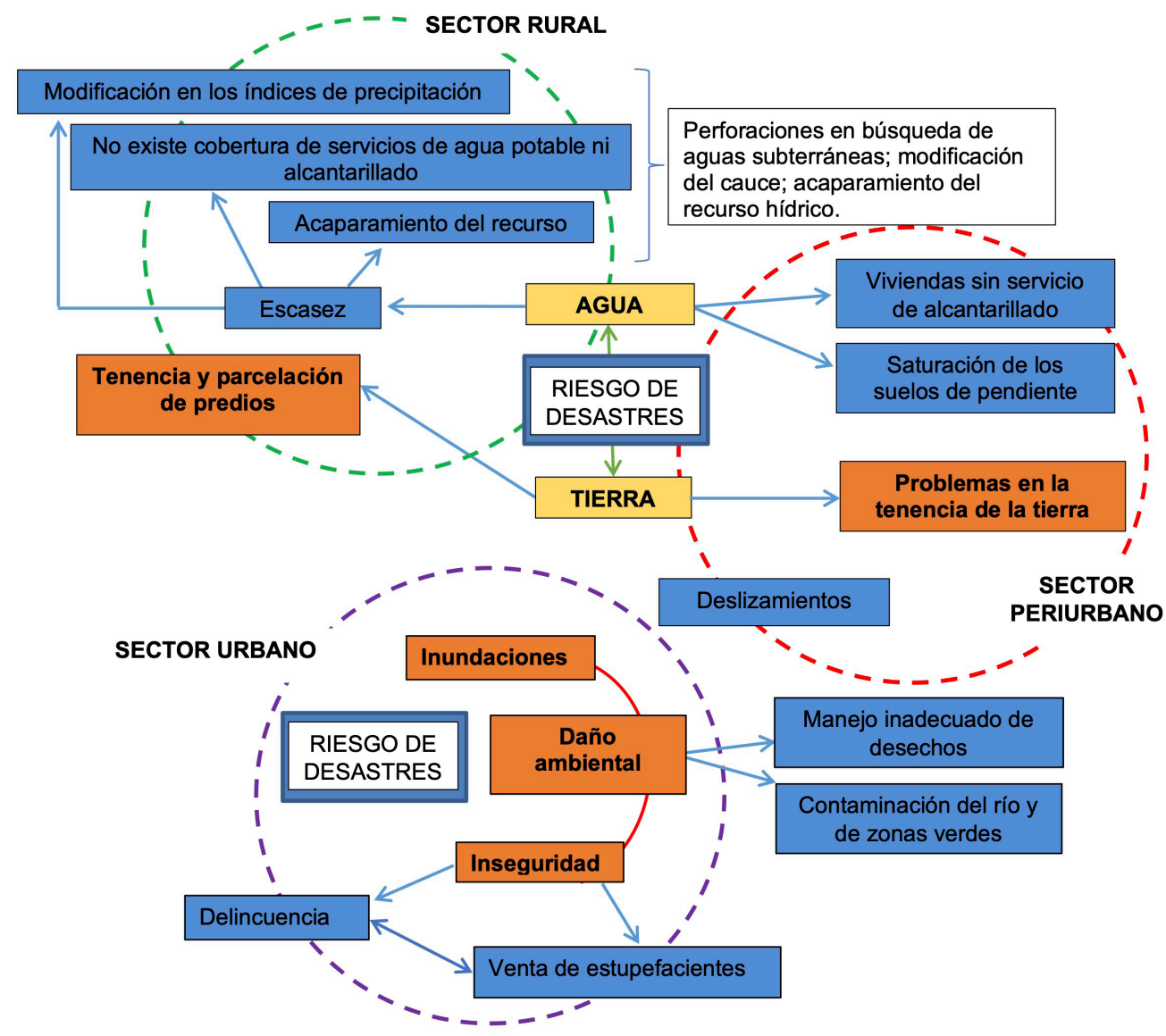

Figura 7. Diagnóstico de vulnerabilidad-amenaza del municipio de Piedecuesta Fuente: Autora, 2022, con datos de campo 


\section{Segundo momento. La imagen del riesgo de desastres y sus implicaciones socioterritoriales}

La cartografía social del sector de Nueva Colombia muestra un paisaje de contraste que ocupa un espacio intermedio entre lo rural y lo urbano (ver Figura 8). La periferia es representada como un territorio híbrido, en donde se contraponen elementos propios de un espacio intervenido para la urbanización (caminos, rutas del transporte municipal, alumbrado público), como las características del entorno natural (laderas, vegetación, terrenos saturados de agua) que, además, posibilitan la reproducción de prácticas agrícolas heredadas.

Las historias de las familias fundadoras del asentamiento que se remiten a más de 25 años atrás, relatan las primeras prácticas de adecuación de los terrenos encontrados en el municipio de llegada (Piedecuesta): los trabajos de deshierbo y limpieza de los terrenos, las labores de vigilancia para alertar sobre la presencia de fuerzas de seguridad, la delimitación de predios y la construcción de las casas, todas estas fueron acciones desarrolladas por el grupo fundador para asegurar una primera etapa de emplazamiento y un ingreso económico, ya que los predios no utilizados se vendían, sin estar regularizados.

La distribución inicial de terrenos fue definiendo ciertas características de organización espacial que se relacionan con conocimientos y prácticas ante el riesgo; por ejemplo, los lugares de planicie y más alejados del río fueron ocupados rápidamente por los primeros pobladores como una estrategia para el ahorro de tiempo, trabajo y recursos en la edificación de las viviendas, así como medida de seguridad ante el peligro por deslizamientos e inundaciones. Las zonas de mayor exposición percibida corresponden a terrenos que se ocuparon por nuevos moradores, tal es el caso del sector de "Las Margaritas" y el "Plan Chino" (sector cuatro), de la manera como se identifican en la Figura 8. En la cartografía social se grafican prácticas asociadas al aprovechamiento de recursos naturales en el emplazamiento (la madera se ha utilizado para la construcción de casas y la preparación de los alimentos), así como el cultivo de hortalizas y la crianza de animales domésticos. Es importante señalar que estas actividades, muy comunes desde la creación del asentamiento, han perdido vigencia como resultado de la amenaza constante por deslizamientos en la zona -mitigando la tala de árboles por recomendación de autoridades y líderes comunitarios-, la baja productividad del suelo y la inseguridad por robos.

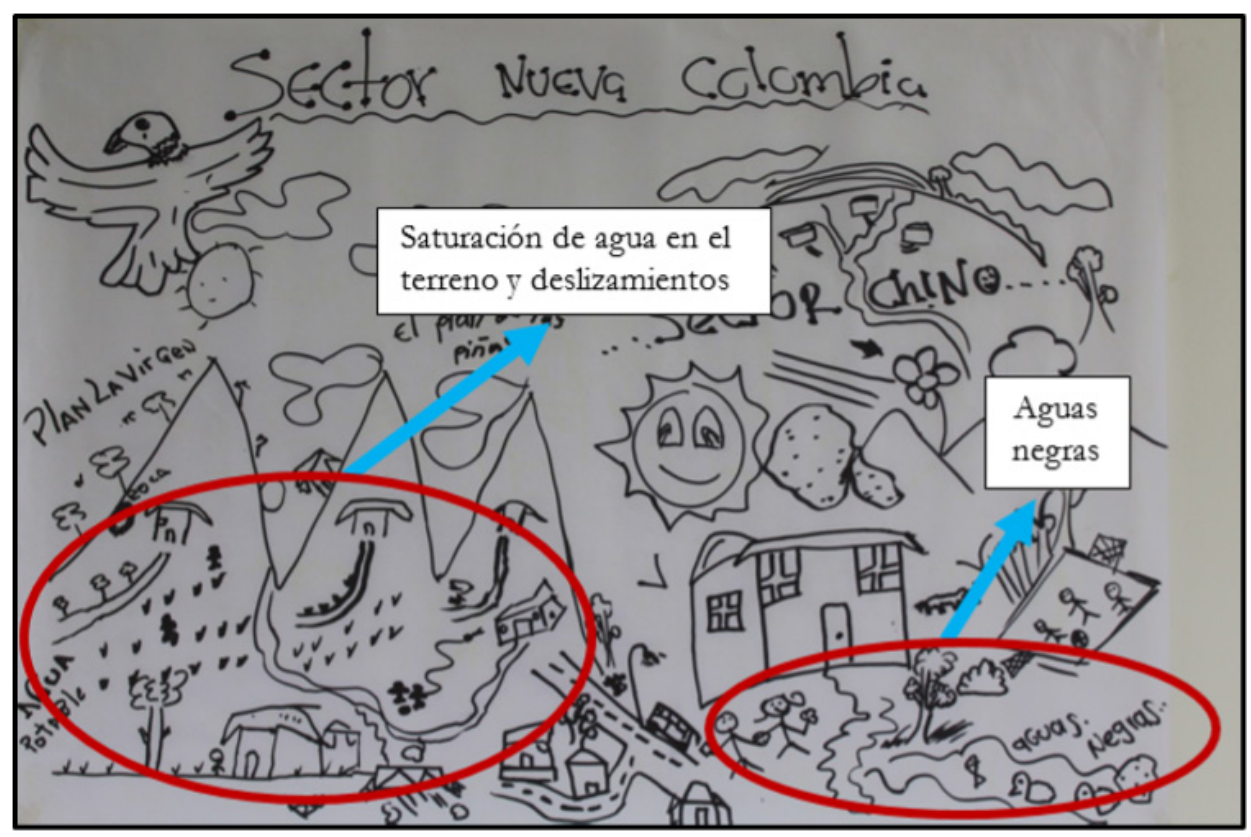

Figura 8. Cartografía social, sector Nueva Colombia (periferia)

Fuente: Habitantes del sector periférico, 2019, modificada por la autora.

Respecto al ejercicio cartográfico del área rural, este adopta las características de un mapa en tanto que puntualiza en los límites de los predios, el tipo de actividades económicas desarrolladas en las parcelas y establecimientos del sector, el trazo de caminos y carreteras, el curso de los ríos y zonas inundables, el bajo caudal de las fuentes hídricas -por acaparamiento y disminución de lluvias-, las fronteras de la vereda y algunos sitios más representativos del lugar ${ }^{7}$ (ver Figura 9).
7. Se ubica en el mapa el famoso "Salto del Duende", formación montañosa con acantilados saturados de vegetación y una cascada que se forma principalmente en temporada de lluvias. 


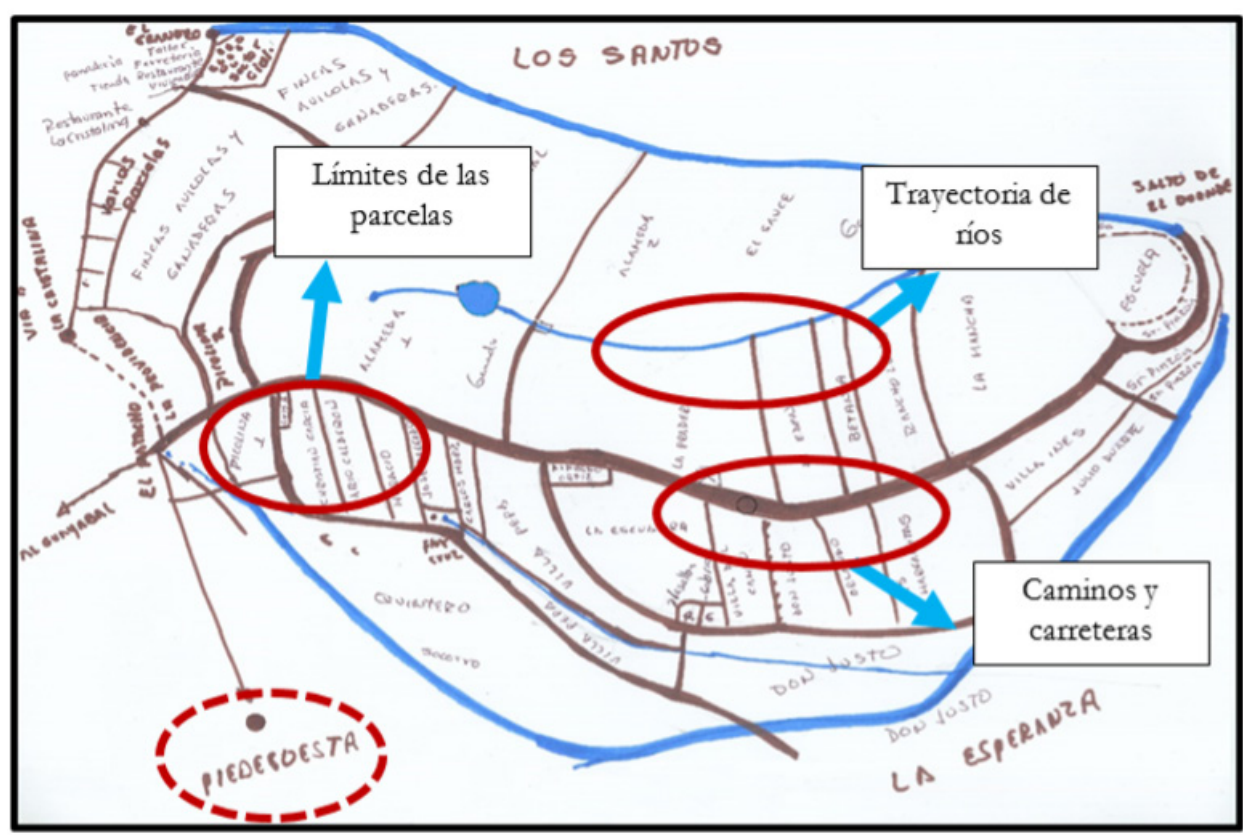

Figura 9. Cartografía social, vereda El Duende (zona rural)

Fuente: Habitantes del sector rural, 2019, modificada por la autora.

Además de la ubicación geográfica de los elementos más evocados, el producto cartográfico de la vereda El Duende también georreferencia el conjunto de relaciones que se desenvuelven territorialmente en contextos de vulnerabilidad y amenaza. Así entonces, el conflicto derivado del acaparamiento de recursos por parte de las avícolas del sector, coexiste con vínculos de convivencia vecinal que se representan mediante puntos de encuentro comunitario: los sujetos grafican algunas prácticas de acaparamiento como la construcción de lagos artificiales -prácticas que han generan relaciones de conflicto-, pero también identifican los escenarios de convivencia en donde se desarrollan diferentes actividades organizadas por la Junta de Acción Comunal (Colegio Holanda- Sede E, El Duende). Otro aspecto a rescatar es la construcción de fronteras simbólicas que separan la vereda y el municipio de Piedecuesta, administración territorial de la que hace parte. El punto con el nombre "Piedecuesta" en realidad representa el casco urbano de la localidad, lo cual evidencia el carácter distante en las relaciones campo-ciudad, agudizado por la histórica indiferencia de los gobiernos municipales ante las problemáticas del sector.

Finalmente, el territorio urbano es representado desde la cartografía social como un espacio simplificado, geométrico y de trazos definidos, pero con problemáticas sociales muy complejas (ver Figura 10). El material cartográfico puntualiza tanto en la identificación de los riesgos y peligros (inseguridad, baches y falta de pavimentación, deficiencia en la señalización, contaminación, amenaza por inundación), como en la georreferenciación de cada uno de los objetos que componen el paisaje. El muro de contención, por ejemplo, se presenta como un elemento distintivo en la recreación del espacio, en tanto que marca las fronteras que protegen de las amenazas físicas (inundaciones) y separan de las vulnerabilidades extendidas de otras realidades colindantes (asentamientos precarios).

La configuración de estos límites espaciales se vincula con el ejercicio consensuado que busca discernir entre los riesgos "endémicos" (contaminación ambiental, daño de la infraestructura urbana) y los riesgos transferidos (venta de estupefacientes, robos, inseguridad), ejercicio que, simultáneamente, recrea las relaciones sociales que se han establecido al interior y con otros territorios; las relaciones de tensión con la población de la periferia municipal, la casi nula interacción con la escena rural y la dinámica de intercambio con barrios cercanos. Tales formas de organización que se fijan desde el saber-hacer territorial, son parte del constructo social y la representación del riesgo de desastres. 


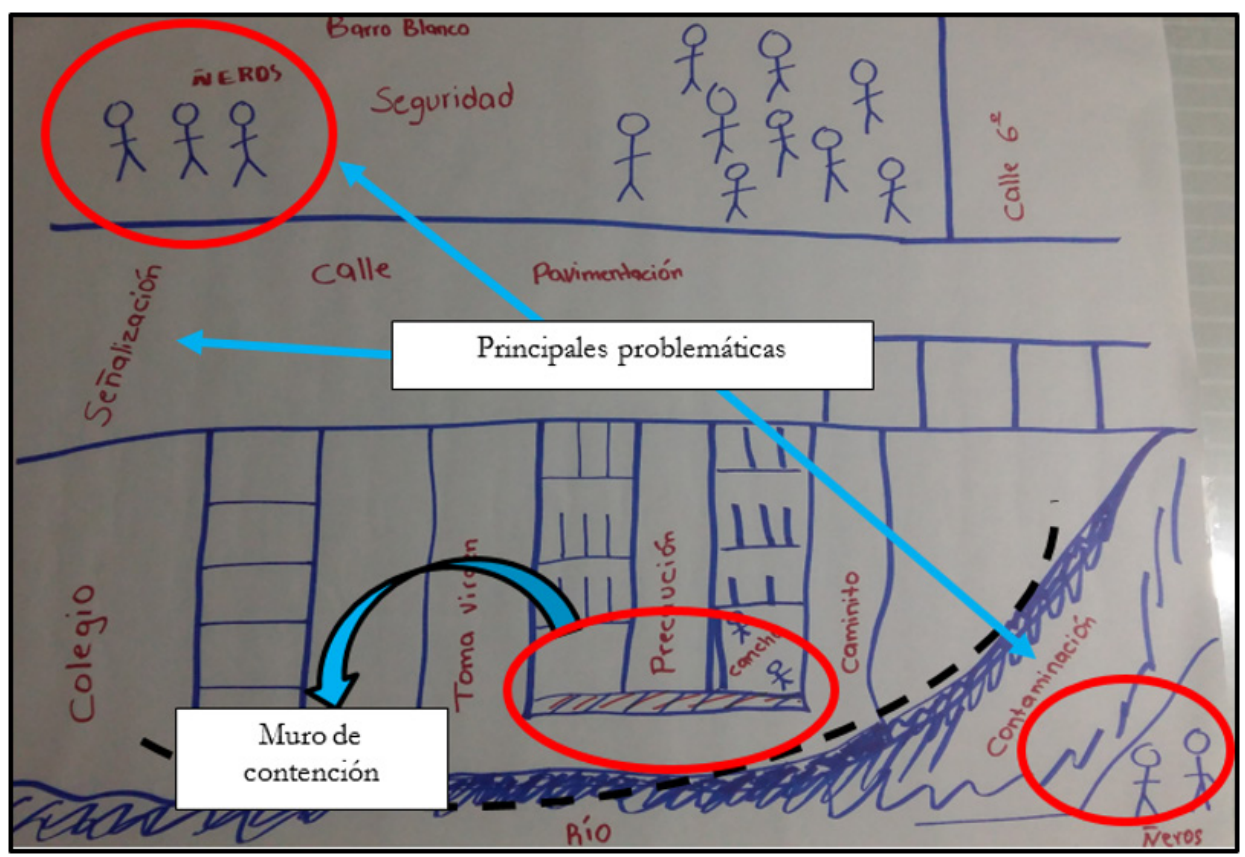

Figura 10. Cartografía social, barrio Barro Blanco (zona urbana) Fuente: Habitantes del sector urbano, 2019, modificada por la autora.

\section{DISCUSIÓN}

Las RS del riesgo de desastres son líneas del texto territorial, en tanto que el territorio, ya acordado como una construcción social, remite al ámbito totalizante-integrador de los elementos -materiales y simbólicos- y relaciones que integran el objeto de estudio.

Los desastres pueden considerarse como una representación abreviada de los diferentes estados de la territorialización: la des-re-territorialización. Los efectos iniciales y prolongados de la confluencia de exposición, vulnerabilidad y amenaza, están directamente vinculados a presiones extremas que se ejercen sobre el territorio, sobre todo en los reducidos tiempos de impacto y posemergencia. La narrativa del riesgo se compone, en los tres grupos de estudio, de relatos sobre la construcción, pérdida y reapropiación de los espacios habitados.

La pérdida de control y poder sobre el espacio no solamente es una consecuencia de la materialización del riesgo, también se configura como una causa del desastre, teniendo en cuenta que gran parte de la población afectada por eventos naturales, socionaturales y antropogénicos, comparte contextos históricos de conflicto territorial.

Es importante rescatar que el discurso también incorpora la memoria de los lugares de origen "ya no habitados" que siguen "vivos" en el imaginario del sujeto social, tal como se evidenció en la narrativa de la periferia urbana. Algunos autores abordan el concepto de re-desterritorialización (García, 2013; Argudo, 2019) para explicar el dominio y control que, a la distancia, puede ejercer un grupo de personas sobre un espacio que ya no habita físicamente. En el contexto de desplazamiento en Colombia, las condiciones forzadas y violentas del desarraigo anulan casi por completo el control directo de los antiguos pobladores sobre las tierras de origen. El proceso de influencia en este caso ocurre a la inversa, es decir, los imaginarios y memorias asociadas a las lejanas vivencias territoriales, mantienen una importante incidencia en los mecanismos de construcción y organización de nuevos espacios. En este sentido, la apropiación de nuevas tierras supone, simultáneamente, la recreación del espacio perdido.

La apropiación de facto realizada por los fundadores de Nueva Colombia -tal vez haciendo apología a la esperanza de un nuevo país- se ha mantenido como una forma permanente de reterritorialización, ante la negativa de la municipalidad del reconocimiento de tenencia. También ha operado como mecanismo de recreación del espacio "no habitado", reconstruyendo un territorio con evidentes vestigios rurales que les permite mantener prácticas asociadas al lugar de origen.

Al igual que el caso de la periferia, la des-re-territorialización en lo rural abandona el esquema cíclico para manifestarse como una serie de ejercicios cotidianos de construcción y deconstrucción 
territorial, debido en parte a aquella experiencia espacial que es definida en ambientes de tensión. La propiedad territorial [física y simbólica] genera certidumbre, por lo que la falta de certeza respecto a la tenencia del territorio y al libre aprovechamiento de sus recursos, es un riesgo. La mitigación de los contextos riesgosos y vulnerables va de la mano del perfeccionamiento de diferentes modos de ocupación que definen ciertas materialidades del espacio (cercado de terrenos con linderos de madera, modificación del curso de los ríos y construcción de aljibes). Estas materialidades son prácticas objetivizadas que se sustentan de una producción constante y sinérgica de conocimientos sobre el medio y los riesgos que coexisten territorialmente. En el caso de la zona de estudio, este tipo de conocimiento entra en el detalle, tal como se percibe claramente en la cartografía de la vereda El Duende.

En perspectiva, el territorio es el marco de encuentros y desencuentros, es la base de la trama relacional que da vida y movimiento al espacio. La comprensión de la des-re-territorialización en el área rural, como proceso cotidiano, requiere de la conjugación de tiempos que da paso a la lectura semántica del espacio, recordando que la reflexión del territorio ha abandonado el plano abstracto para recrear un escenario que existe como organismo, medio y vínculo.

Ya Souza (1995) ha establecido los conceptos de territorialidad móvil y cíclica para hacer referencia a las espacialidades que se caracterizan por el control territorial intermitente entre grupos de poder. En el caso de las ciudades y zonas metropolitanas, las temporalidades de la territorialización suelen relacionarse con los horarios establecidos por ciertos colectivos para el desarrollo de actividades que desplazan la cotidianidad (venta y consumo de drogas, por ejemplo). Así entonces, las estrategias de reterritorialización en la zona urbana municipal se han centrado en acciones de vigilancia y alerta vecinal que los proteja de riesgos asociados a la inseguridad ciudadana, como una forma de control y [re] apropiación del territorio disputado.

La socioterritorialidad desde la dinámica urbana cobra un nuevo sentido, en tanto que es un espacio en donde se identifican, más fácilmente, ciertos rasgos de desprendimiento de la vida social respecto de un único territorio (Beraún y Beraún, 2009). Gran parte de la vida social, académica y laboral de la población urbana de Piedecuesta se desarrolla en Bucaramanga, lo cual deriva en un flujo diario y constante de personas entre el municipio y la capital departamental.

La des-re-territorialización urbana se relaciona con este movimiento pendular. Las sinergias cotidianas de movilización pueden abordarse como experiencias combinadas de desarraigo y reapropiación espacial, marcadas por los tiempos rutinarios. Como corolario, la experiencia urbana se caracteriza por una territorialidad diversa o multiespacialidad, y por un ejercicio continuo de valoración de los diferentes lugares en que se desarrolla la praxis social, aunque los problemas que afectan al espacio residencial y familiar mantienen mayor incidencia en la configuración narrativa del riesgo de desastres.

\section{REFLEXIONES CONCLUSIVAS}

El riesgo de desastres y el territorio tienen una característica común: son construcciones sociales. La producción y reproducción de condiciones de vulnerabilidad se desarrolla en un espaciotiempo que, en simultáneo, es intervenido tanto por las particularidades físicas-simbólicas de los componentes del riesgo, como por los conocimientos y prácticas que se gestan colectivamente en torno a este.

Para el caso de la zona de estudio, las narrativas e imágenes elaboradas socialmente en torno a la noción del riesgo se encuentran fuertemente unidas al plano territorial. Los procesos de ocupación y adaptación del espacio habitado por los grupos rurales, urbanos y periurbanos, se relacionan y a la vez inciden en la generación de diversas representaciones sociales sobre los desastres. Los problemas de tenencia de tierra o las disputas por el control de los espacios públicos, por ejemplo, son experiencias cotidianas que orientan las prácticas y las interacciones de los sujetos ante un riesgo catalogado como "permanente".

La socioterritorailidad del riesgo corresponde a esa lectura espacial que los sujetos cognoscentes realizan a partir de la representación de los factores que interactúan en los procesos de desastre. El vínculo sinérgico entre territorio y riesgo se sustenta en el hecho de que los conocimientos y prácticas frente a los desastres -que integran el sistema de sentido comúninciden en la forma en que los grupos sociales crean, organizan y transforman su territorio, a la vez que las RS del riesgo también se configuran desde un plano socioterritorial. Dicha complejidad 
del objeto de estudio ratifica la pertinencia de una triangulación metodológica que, en este caso, se ha nutrido de instrumentos, conceptos y enfoques tomados de las investigaciones sociales de los desastres y la TRS.

La noción de socioterritorio permite definir la materialidad y subjetividad que expresan acciones y saberes, el conjunto de relaciones que caracterizan al fenómeno representacional y la agencia socioespacial de los grupos urbanos, rurales y periféricos de la zona. Como corolario, la incidencia territorial del riesgo puede ser entendida desde el abordaje de los procesos de redes-territrorialización, en la medida en que los impactos y efectos de los desastres suponen, paralelamente, realidades de despojo, oportunidades de apropiación y contextos de reapropiación espacial.

Cabe destacar que la entidad territorial, desde el enfoque de construcción social, no es unidimensional, ni mucho menos fija, condición que también adopta la noción de riesgo. Este hecho explica las narrativas disímiles y la pluralidad de elementos que integran las diferentes imágenes elaboradas por la población en la identificación de vulnerabilidades y amenazas, lo cual se relaciona con la diversidad de fuentes y medios que el sujeto social utiliza para elaborar conocimientos y orientar sus acciones. La integración del enfoque social de los desastres y la teoría moscoviciana, como marco interpretativo de los sistemas de afianzamiento del saber-hacer común, constituye una visión novedosa en la medida en que se transita del hecho al sentido en el afrontamiento de la incertidumbre, en una investigación que ha buscado sobrepasar el ¿qué hacer? de los estudios tradicionales sobre riesgo y desastres, al ¿por qué se hace? del universo simbólico. El presente artículo pretende estimular el necesario debate en torno a la inclusión de este tipo de análisis para el diseño de políticas sobre la gestión integral y la RRD.

\section{REFERENCIAS}

Abric, J.C. (2001). Prácticas sociales y representaciones, México: Ediciones Coyoacán.

Alcaldía de Piedecuesta. (2020). Plan de Desarrollo de Piedecuesta 2020-2023. Una ciudad para la gente, Piedecuesta. https://ng.cl/kvx5f

Anderson, M. \& Woodrow, P. (1989). Rising from the Ashes: Development Strategies in Times of Disasters, Boulder: Westview Press. (Reeditado en 1998 por Intermeditate Technology, Londres).

Argudo, A. (2019). Copal ¿Un pueblo fantasma? Religiosidad y comunidad re-desterritorializada. Yachana Revista Científica, 8(3), 1-11. http://repositorio.ulvr.edu.ec/handle/44000/3640

Beraún, J.J., \& Beraún, A.J. (2009). Sociedades territorializadas: desterritorialización y reterritorialización en Lima Metropolitana. Ensayos en Ciencias Sociales, 3, 109-142.

Beck, U. (2002). La sociedad del riesgo global. Madrid: Siglo XXI de España Editores.

Chmutina, K., von Meding, J., Sandoval, V., Boyland, M., Forino, G., Cheek, W., Williams, D.A., Gonzalez-Muzzio, C., Tomassi, I., Páez, H. \& Marchezini, V. (2021). What We Measure Matters: The Case of the Missing Development Data in Sendai Framework for Disaster Risk Reduction Monitoring. International Journal Disaster of Risk Science. https://doi.org/10.1007/ S13753-021-00382-2

Colombani, M.C. (2008). A propósito de Dioniso y Apolo. Mismidad y Otredad: el juego de las tensiones. Nuntius Antiquus, (2), 25-40. https://n9.cl/8uvp9

Consejo Municipal para la Gestión del Riesgo de Desastres (CMGRD). (diciembre 2013). Plan Municipal de Gestión del Riesgo de Desastres (PMGR), Piedecuesta.

Calixto, R. (2008). Representaciones sociales del medio ambiente. Perfiles educativos, 3o(120), 33-62.

De Alba, M. (2004). Mapas mentales de la Ciudad de México: una aproximación psicosocial al estudio de las representaciones sociales. Estudios Demográficos y Urbanos, 19(1), 115-143.

De Alba, M. (2006). Experiencia urbana e imágenes colectivas de la Ciudad de México. Estudios Demográficos y Urbanos, 21(3), 663-700.

Departamento Administrativo Nacional de Estadística, DANE. Proyecciones de población municipales por área, 2018 [Base de datos]. https://ng.cl/go5u4

Espinosa, D. (2020). El Policía Ambiental en el Valle de Aburrá: Un estudio de Representaciones Sociales de Educación Ambiental y Medio Ambiente. Cadernos de Dereito Actual, 1(13), 457-473.

García, A. (2013). Territorios disputados. Revista de Estudios del Pacífico, 1(2), 69-114. 
García, V. (septiembre-diciembre 2005). El riesgo como construcción social y la construcción social de riesgos. Desacatos. Revista de Antropología Social, (19), 11-24.

Gellert de Pinto, G. (2012). El cambio de paradigma: de la atención de desastres a la gestión del riesgo. Boletín Científico Sapiens Research, 2(1), 13-17.

Haesbaert, R. (2013). Del mito de la desterritorialización a la multiterritorialidad. Cultura y representaciones sociales, $8(15)$, 9-42. https://ng.cl/mko4s

Hewitt, K. (1983). “The Idea of Calamity in a Technocratic Age”. En: K. Hewitt (Ed), Interpretations of Calamity. Boston: Allen and Unwin, pp. 3-32.

Jerez-Ramírez, D. (2018). Construcción social del riesgo de desastres en el Municipio de Piedecuesta, Santander (Colombia): dimensiones socio-representacionales. (Tesis de doctorado). Universidad Nacional Autónoma de México, Programa de Posgrado en Ciencias Políticas y Sociales, Facultad de Ciencias Políticas y Sociales, Ciudad de México, México. [Biblioteca UNAM].

Lavell, A. (1996). Degradación ambiental, riesgo y desastre urbano. Problemas y conceptos: hacia la definición de una agenda de investigación. En: M. Augusta Fernández (comp.), Ciudades en riesgo. Degradación ambiental riesgos urbanos y desastres. La Red/ USAID, Colombia, 2-30.

Lavell, A. (2004). Vulnerabilidad social: Una contribución a la especificación de la noción y sobre las necesidades de investigación en pro de la reducción del riesgo. En: Memoria del Seminario Internacional Nuevas Perspectivas en la Investigación Científica y Técnica para la Prevención de Desastres, 24-26 de noviembre de 2004, Lima: Sistema Nacional de Defensa Civil/Perú; Save the Children/Suecia; itdg, 48-55.

Leff, E. (2004). Racionalidad ambiental y diálogo de saberes. Significancia y sentido en la construcción de un futuro sustentable. POLIS, Revista Latinoamericana, 2(7). https://ng.cl/i6dte

Luhmann, N. (2006). Sociología del Riesgo. México: Universidad Iberoamericana.

Martínez, M. (2011). Los geógrafos y la teoría de riesgos y desastres ambientales. Perspectiva Geográfica, 1(14), 241-263. https://n9.cl/455qf

Martínez, M. (2015). Entre la imagen y la palabra: representaciones infantiles del tejido de palma entre los mixtecos contemporáneos de Santiago Cacaloxtepec. Cuicuilco, 22(64), 245-267. https:// n9.cl/tgue2

Milgram, S. \& Jodelet, D. (1976). "Psychological maps of Paris”. In H.M. Proshansky, W.H. Ittelson \& L.G. Rivlin (Eds.). Environmental psychology: people and their physical settings. New York: Holt Rinehart and Winston.

Mora, M. (2002). La teoría de las representaciones sociales de Serge Moscovici. Athenea Digital, (2), 1-25. https://raco.cat/index.php/Athenea/article/view/34106

Moscovici, S. (1976). La Psychanalyse: Son image et son public. Paris: Presses Universitaires de France.

Oliver-Smith, A., Alcántara-Ayala, I., Burton, I. \& Lavell, A. (2017). “The social construction of disaster risk: Seeking root causes”. International Journal of Disaster Risk Reduction, 22, 469-474. https://doi. org/10.1016/j.ijdrr.2016.10.006

Organización de las Naciones Unidas (ONU). "Resolución A/RES/55/2 Declaración del Milenio”, 13 de septiembre de 2000. [Edición electrónica]. https://ng.cl/vn91l

ONU, "Resolución A/RES/70/1 - Transformar nuestro mundo: la Agenda 2030 para el Desarrollo Sostenible”, 21 de octubre de 2015. [Edición electrónica]. https://n9.cl/61b8t

ONU, “Conferencia Mundial sobre la Reducción de los Desastres. Marco de Acción de Hyogo para 20052015: Aumento de la resiliencia de las naciones y las comunidades ante los desastres”, enero 2005 , Kobe, Hyogo. [Edición electrónica]. https://ng.cl/bujlb

ONU. (2009). Estrategia Internacional para la Reducción de Desastres. Terminología sobre Reducción de Desastres, Ginebra: UNISDR.

Nuño, B. (2004). Modelos de toma de decisiones con los que intentan resolver el consumo de drogas ilegales adolescentes consumidores y sus padres que acuden a tratamiento a CIJ en Guadalajara. (Tesis de doctorado). Universidad Nacional Autónoma de México, Programa de Maestría y Doctorado en Psicología, Ciudad de México.

Palazuelos, I. (2012). La desconfianza en los partidos políticos y la percepción ciudadana de desempeño gubernamental: México ante América Latina. Revista Mexicana de Análisis Político y Administración Pública, 1(1), 79-107. 
Pérez, A. (2012). La integración de la gestión de riesgos en la gestión del desarrollo local desde la perspectiva de la vulnerabilidad ambiental en los territorios. DELOS, Revista Desarrollo Local Sostenible, 5(13),1-7. https://ng.cl/solf

Preciado, J. (2007). Análisis de riesgo en la región de la Sierra Norte de Puebla: El papel de la vulnerabilidad y la inestabilidad de laderas. (Tesis de licenciatura). Universidad Nacional Autónoma de México, Facultad de Filosofía y Letras, Colegio de Geografía, Ciudad de México, México. Biblioteca UNAM.

Ramos, R. (2006). "La deriva hacia la incertidumbre de la sociedad del riesgo". En: Juan de Dios Ruano (Dir.), I Jornadas sobre gestión de crisis. Más allá de la sociedad del riesgo. Universidade da Coruña. A Coruña, 27-43.

Reigota, M. (1990). Les représentations sociales de l'environnement et les pratiques pédagogiques quotidiennes des professeurs de Sciences a São Paulo-Brésil (Tesis doctoral en Pedagogía Biológica). Louvain-la Neuve: Université Catholique de Louvain, UCL.

República de Colombia-DANE. Censos de Población y Vivienda (1938, 1985, 1993, 2018).

Rubio, I. (2012). La estructura de vulnerabilidad y el escenario de un gran desastre. Investigaciones geográficas, (77), 75-88. https://ng.cl/rrfig

Sánchez, A.G. (2013). Territorios disputados. Revista de Estudios del Pacífico, 1(2), 69-114.

Sandoval-Díaz, J. (2020). Vulnerabilidad-resiliencia ante el proceso de riesgo-desastre: Un análisis desde la ecología política. Polis, 19(56), 214-239. https://ng.cl/3bgyt

Serrano, E. (2010). La construcción social y cultural de la maternidad en San Martín Tilcajete, Oaxaca. (Tesis de doctorado). Universidad Nacional Autónoma de México, Posgrado en Antropología, Facultad de Filosofía y Letras, Instituto de Investigaciones Antropológicas, Ciudad de México, México. [Biblioteca UNAM].

Sevillano, M.E. (2021). Método de Evaluación Sintetizada para Riesgo de Desastres con Enfoque de Ordenamiento Territorial (MESR): Una aplicación para la ciudad de Cali, Colombia. Revista de Estudios Latinoamericanos sobre Reducción del Riesgo de Desastres REDER, 5(1), 46-69. http:// revistareder.com/handle-0719-8477-2020-070

Souza, M.J.L.D. (1995). O território: sobre espaço e poder, autonomia e desenvolvimento. Geografia: conceitos e temas. Rio de janeiro: Bertrand Brasil, 353, 77-116.

Toscana, A. \& Valdez, V. (2014). Representaciones sociales del desastre de 1940 en Santa Cruz Pueblo Nuevo, Estado de México. Investigaciones Geográficas, (83), 88-101. http://doi.org/10.1435o/rig.36918

Wilches-Chaux, G. (1993). "La Vulnerabilidad Global”. En: A. Maskrey (Comp.), Los desastres no son naturales. Bogotá: Red de Estudios Sociales en Prevención de Desastres en América Latina/La Red/ Tercer Mundo Editores, 11-44. 